\title{
Detection of viable enterotoxin-producing Bacillus cereus and analysis of toxigenicity from ready-to-eat foods and infant formula milk powder by multiplex PCR
}

\author{
Zhihong Zhang, ${ }^{*}$ Lixia Feng, ${ }^{*}$ Hengyi $X u,{ }^{*}$ Chengwei Liu, $†$ Nagendra P. Shah, $\ddagger$ and Hua Wei ${ }^{* 1}$ \\ *State Key Laboratory of Food Science and Technology, Nanchang University, Nanchang 330047, China \\ †Institute of Nutrition and Food Safety, Jiangxi Provincial Centre for Disease Control, Nanchang 330046, P. R. China \\ ‡Food and Nutritional Science, School of Biological Science, The University of Hong Kong, Pokfulam Road, Hong Kong, China
}

\begin{abstract}
Bacillus cereus is responsible for several outbreaks of foodborne diseases due to its emetic toxin and enterotoxin. Enterotoxins, cytotoxin K (CytK), nonhemolytic enterotoxin (Nhe), and hemolysin BL ( $\mathrm{Hbl}$ ), have been recorded in several diarrheal cases due to food poisoning from $B$. cereus. The objective of this study was to develop a rapid and accurate method that combines multiplex PCR with propidium monoazide to selectively detect viable cells of enterotoxin-producing $B$. cereus in milk powder, noodles, and rice, and investigate the distribution of enterotoxins in 62 strains of $B$. cereus in Jiangxi province, China. The specificity of primers of 3 enterotoxins (i.e., cytK, nheA, and hblD) of $B$. cereus was verified by inclusivity and exclusivity tests using single PCR. Upon optimization of multiplex PCR conditions, it was found that the detection limit of viable cells was $10^{2} \mathrm{cfu} / \mathrm{mL}$ of $B$. cereus in pure culture. By enrichment for 3 or $4 \mathrm{~h}$ and propidium monoazide pretreatment, a protocol for detection of viable cells as low as $2.2 \times 10^{1} \mathrm{cfu} / \mathrm{g}$ in spiked food (e.g., milk powder, noodles, and rice) was established and proved valid even under the interference of non-Bacillus cereus at as high as $10^{5} \mathrm{cfu} / \mathrm{g}$. Moreover, the protocol based on multiplex PCR for detection was applied for the analysis of distribution of toxin gene of $B$. cereus, and the results showed a regional feature for toxin gene distribution, indicating that potential toxigenicity of $B$. cereus should be evaluated further.
\end{abstract}

Key words: Bacillus cereus, enterotoxin-producing, multiplex PCR, propidium monoazide, toxigenicity

\section{INTRODUCTION}

Bacillus cereus is a ubiquitously distributed soil microorganism associated with reheated or inadequately

Received July 21, 2015.

Accepted September 27, 2015.

${ }^{1}$ Corresponding author: weihua114@live.cn cooked foods [e.g., fried rice, noodles, milk, and other dairy products (Stenfors Arnesen et al., 2008; Hwang and Park, 2015)]; it could colonize the gut of humans and invertebrates as an opportunistic pathogen (Ghosh, 1978; Jensen et al., 2003) resulting in bacteremia, meningitis, endophthalmitis, and pneumonia in hospitals (Bottone, 2010). It also gives rise to white patch disease on Litopenaeus vannamei, leading to gradual mortality (Velmurugan et al., 2015).

For 6 decades, foodborne diseases from B. cereus occurred mostly in European countries and North America (Beattie, 1999; Hwang and Park, 2015) since its first outbreak in Norway during 1947 to 1949 (Hauge, 1950, 1955). Due to strong thermotolerance of spores against high pasteurization temperature, $B$. cereus has become a frequent foodborne disease worldwide (Singh and Chaturvedi, 2015). For instance, a healthy 39-yr-old woman started vomiting and suffered from watery diarrhea after eating microwave-heated chicken (López et al., 2015). It was demonstrated that toxin led to the typical symptoms of emesis and diarrhea due to consumption of food contaminated with $B$. cereus ( $>10^{5} \mathrm{cfu} / \mathrm{g}$; Hwang and Park, 2015). Emetic toxin was attributed to peptide cereulide, a thermostable and acid-resistant depsipeptide toxin. Among those toxins causing diarrhea, 5 enterotoxins have been commonly studied. Nonhemolytic enterotoxin (Nhe) and hemolysin BL $(\mathbf{H b l})$ are both composed of 3 proteins, whereas cytotoxin K (CytK), enterotoxin FM (EntFM), and BceT are composed of 1 protein only (Hwang and Park, 2015). The Nhe complex is encoded by nheA, nheB, and $n h e C$, and the $\mathrm{Hbl}$ complex by $h b l A$, hblC, and $h b l D$ (Bonerba et al., 2010). The CytK toxin induces diarrhea similar to Nhe and Hbl toxins (Lund and Granum, 1997). In those 5 toxins, only Nhe, Hbl, and CytK were demonstrated to be responsible for food poisoning in the gastrointestinal tract (Fagerlund et al., 2010; Berthold-Pluta et al., 2015; Hwang and Park, 2015).

Generally, rapid, accurate, and internationally accepted methods for determining the causes of foodborne pathogens are of utmost importance for the clinical 
diagnostics and monitoring of food hygiene in the food industry (Garrido et al., 2013). The current protocol for detection of $B$. cereus by traditional selective plating and biochemical studies is time consuming and laborious (Zhang et al., 2014). Moreover, conventional media often lead to substantial misidentification and underestimation of B. cereus (Fricker et al., 2008) due to interference by nontarget microorganisms in food samples. Alternatively, PCR is regarded as a promising method for the detection and characterization of bacteria in a wide range of samples (Garrido et al., 2013); multiplex PCR (mPCR) can be used for simultaneous amplification of various specific DNA sequences in a single reaction, with the advantage of saving time and costs (Park and Ricke, 2015). However, the lack of differentiation between DNA from viable and dead cells seriously restricts routine applications of detection methods based on DNA (Nocker et al., 2009; Seinige et al., 2014). Targeting at differentiation of viable and dead cells, pretreatment with DNA-intercalating dyes [e.g., propidium monoazide (PMA) or ethidium monoazide] has been applied to efficiently eliminate falsepositive results due to dead cells. In our previous study, a combination of PMA treatment with $\mathrm{mPCR}$ has been successfully used for the detection of emetic and nonemetic B. cereus (Zhang et al., 2014). Moreover, the universal applicability of that protocol for enterotoxin detection of $B$. cereus needs to be studied.

Therefore, in this study, we developed a PMA combined with mPCR method for simultaneous and selective detection of 3 enterotoxin genes in one type strain of $B$. cereus (ATCC14579), and assessed the general suitability for the toxigenicity characterization of $B$. cereus isolated from ready-to-eat foods and infant formula milk powder. To our knowledge, this is the first study of using PMA-mPCR to set up simultaneous detection of relevant enterotoxin genes (cytK, nheA, and $h b l D$ ) of $B$. cereus involved in several food poisoning cases in humans. This PMA-mPCR protocol might provide a model to set up an efficient detection tool for monitoring food contaminants from pathogens besides $B$. cereus, and thus ensure food safety in ready-to-eat foods or in food processing.

\section{MATERIALS AND METHODS}

\section{Bacterial Strains and Culture Conditions}

Bacillus cereus ATCC14579 was used as a type strain of enterotoxin-positive organism for 3 enterotoxin genes (i.e., cytK, nheA, and hblD; Ngamwongsatit et al., 2008). All bacterial strains belonging to 13 species were listed in Table 1 and used for inclusivity and exclusivity testing. All strains were cultivated accord- ing to their individual protocols. Candida albicans was cultured in yeast extract peptone dextrose medium and Micrococcus luteus in nutrient broth at $30^{\circ} \mathrm{C}$. However, B. cereus and other bacterial strains were cultured in Luria-Bertani medium at $37^{\circ} \mathrm{C}$. All strains were cultured overnight and DNA templates were extracted by boiling method for the inclusivity and exclusivity assay (Zhang et al., 2014).

\section{PMA Pretreatment and Genome DNA Extraction}

The schematic of PMA-mPCR and process of PMA cross-link to DNA are shown in Figure 1 (http://biotium. com/product/pmatm-dye-propidium-monoazide/; van Frankenhuyzen et al., 2011). The PMA only cross-links to DNA of dead cells and eliminate the amplification signal. Dead cell preparation and PMA treatment were carried out as described previously (Zhang et al., 2014). The genome DNA was extracted as follows: $1 \mathrm{~mL}$ of the sample was centrifuged $\left(12,000 \times g, 2 \mathrm{~min}, 4^{\circ} \mathrm{C}\right)$ and suspended in sterilized water using DNeasy Blood \& Tissue Kit (Qiagen, Shanghai, China) according to the manufacturer's instructions. Particularly, the cell pellet was treated with $180 \mu \mathrm{L}$ of enzymatic lysis buffer, and the debris was removed with the aim to enhance DNA purity. The purified DNA was stored at $-20^{\circ} \mathrm{C}$ for further use.

\section{Primer Design}

The primer pairs used for the amplification of enterotoxin genes cytK (GenBank: DQ885233.1), nheA (GenBank: Y19005.2), and hblD (GenBank: U63928.1) are listed in Table 2. The primer was designed using Oligo 7.0 software (Molecular Biology Insights Inc., Colorado Springs, CO), and the specificity of the sequences was tested with the help of the National Center for Biotechnology Information (NCBI; http://blast.ncbi.nlm.nih. gov/Blast.cgi). GenScript Co. Ltd. (Nanjing, China) offers a commercial service for providing primer.

\section{PCR Conditions}

The PMA-mPCR was performed using a final volume of $20 \mu \mathrm{L}$ in the $\mathrm{mPCR}$ system, including $3 \mu \mathrm{L}$ of the genome DNA, $10 \mu \mathrm{L}$ of $2 \times$ Taq mix (Novoprotein Scientific Inc., Shanghai, China), $0.175 \mu M$ of each forward and reverse cytK primer, $0.25 \mu M$ of each forward and reverse nheA primer, and $0.2 \mu M$ of each forward and reverse $h b l D$ primer. Sterilized distilled water was supplemented to a final volume of $20 \mu \mathrm{L}$, and $2 \mu \mathrm{L}$ of paroline was added last for sealing. For single and duplex PCR, all the parameters (the volume of genome DNA and Taq mix) were the same as mPCR except for 
Table 1. Bacterial strains used for inclusivity and exclusivity study of single PCR testing

\begin{tabular}{|c|c|c|c|c|c|}
\hline \multirow[b]{2}{*}{ Bacteria strains } & \multirow[b]{2}{*}{ Strain ID } & \multirow[b]{2}{*}{ Source $^{1}$} & \multicolumn{3}{|c|}{ Single PCR result ${ }^{2}$} \\
\hline & & & cytK & nheA & $h b l D$ \\
\hline Bacillus cereus & ATCC14579 & ATCC & + & + & + \\
\hline Listeria monocytogenes & ATCC13932 & ATCC & - & - & - \\
\hline Candida albicans & ATCC10231 & ATCC & - & - & - \\
\hline Salmonella Paratyphi & ATCC9150 & ATCC & - & - & - \\
\hline Salmonella Anatum & ATCC9270 & ATCC & - & - & - \\
\hline Salmonella Choleraesuis & ATCC10708 & ATCC & - & - & - \\
\hline Salmonella enteritidis & ATCC13076 & ATCC & - & - & - \\
\hline Salmonella Typhimurium & ATCC13311 & ATCC & - & - & - \\
\hline Shigella flexner & ATCC29903 & ATCC & - & - & - \\
\hline \multirow[t]{2}{*}{ Staphylococcus aureus } & CMCC26001 & $\mathrm{CMCC}$ & - & - & - \\
\hline & CMCC26002 & CMCC & - & - & - \\
\hline Serratia marcescens & CMCC41002 & CMCC & - & - & - \\
\hline \multirow{2}{*}{ Enterobacter sakazakii } & CMCC45401 & CMCC & - & - & - \\
\hline & CMCC45402 & $\mathrm{CMCC}$ & - & - & - \\
\hline Micrococcus luteus & CMCC28001 & $\mathrm{CMCC}$ & - & - & - \\
\hline Pseudomonas aeruginosa & CMCC10104 & CMCC & - & - & - \\
\hline Proteus vulgaris & CMCC49101 & $\mathrm{CMCC}$ & - & - & - \\
\hline Escherichia coli O157:H7 & NCTC12900 & NCTC & - & - & - \\
\hline Vibrio parahaemolyticus & PVPA0155 & JX-CDC & - & - & - \\
\hline
\end{tabular}

${ }^{1}$ ATCC $=$ American Type Culture Collection, Rockville, Maryland; CMCC = China Medical Culture Collection, Beijing, China; NCTC = National Collection of Type Cultures, London, UK; JX-CDC = Jiang Xi Province Center for Disease Control and Prevention, Nanchang, China.

${ }^{2}+$ and - indicate positive and negative signal, respectively.
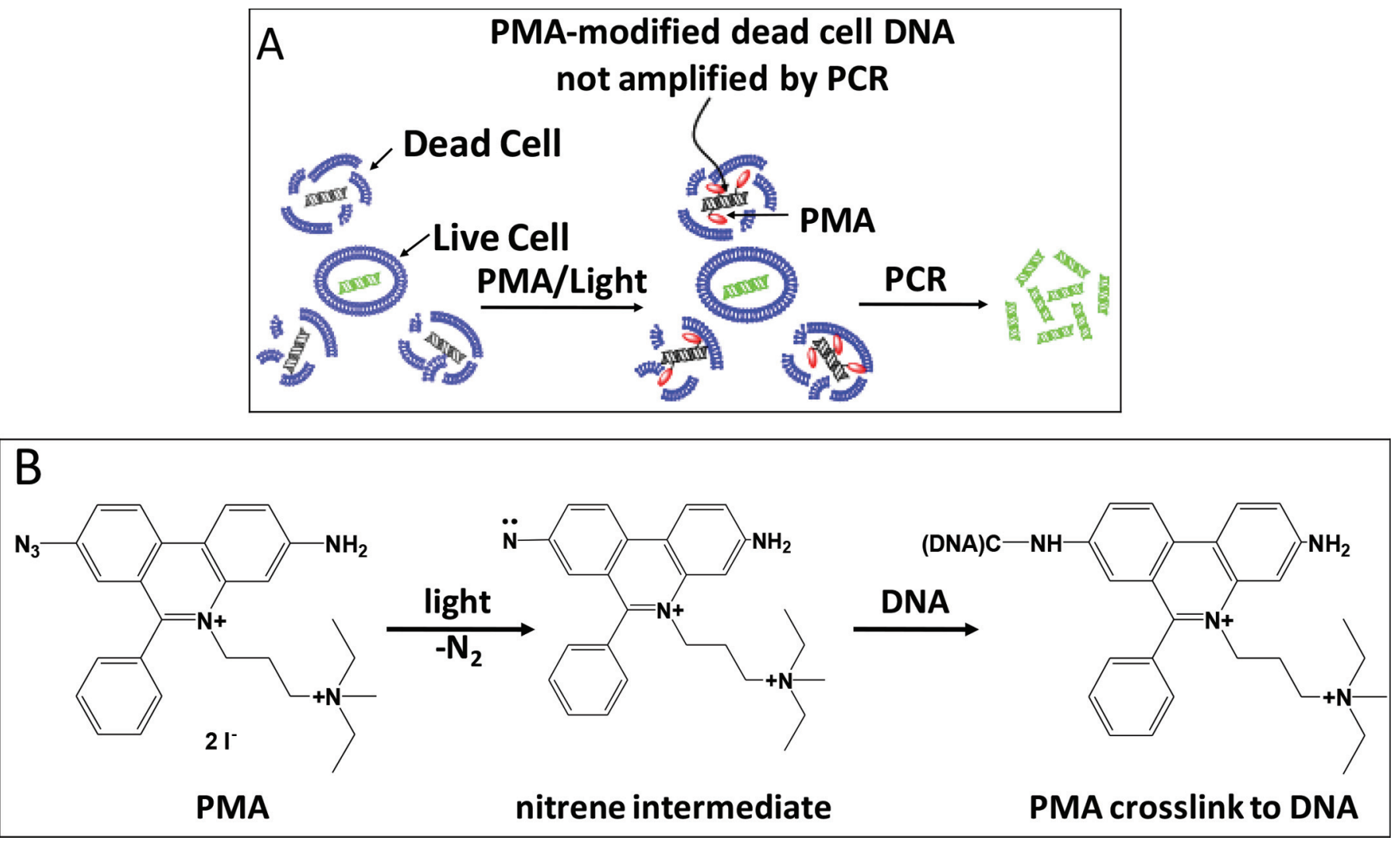

Figure 1. Schematic of selective detection of viable cells using propidium monoazide (PMA)-multiplex PCR (A) and proposed mechanism of PMA covalently cross-linked to DNA (B). Color version available online. 
Table 2. Oligonucleotide primers used in this study $(\mathrm{F}=$ forward; $\mathrm{R}=$ reverse $)$

\begin{tabular}{llcc}
\hline Target & Primer sequence $\left(5^{\prime} \rightarrow 3^{\prime}\right)$ & $\begin{array}{c}\text { Amplicon } \\
\text { length (bp) }\end{array}$ & Reference \\
\hline cytK & $\begin{array}{l}\text { cytK-F: ATCGGTCAAAATGCAAAAACAC } \\
\text { cytK-R: ACCCAGTTACCAGTTCCGAATG }\end{array}$ & 800 & This study \\
nhe $A$ & $\begin{array}{l}\text { nheA-F: AGGTAATGCGATGAGTAG } \\
\text { nheA-R: TTGTTGAATGCGAAGAG }\end{array}$ & 617 & This study \\
hblD & hblD-F: GTTAGATACAGCGAAGCCAC & 465 & This study \\
\hline
\end{tabular}

$0.2 \mu M$ of each primer. The PCR reaction began with 1 cycle of $10 \mathrm{~min}$ at $95^{\circ} \mathrm{C}$, followed by 35 cycles of denaturing at $95^{\circ} \mathrm{C}$ for $30 \mathrm{~s}$, annealing at $52.2^{\circ} \mathrm{C}$ for $30 \mathrm{~s}$, and elongation at $72^{\circ} \mathrm{C}$ for $30 \mathrm{~s}$, and then an extra elongation step of $10 \mathrm{~min}$ at $72^{\circ} \mathrm{C}$. After PCR amplification, the products were removed and subjected to $2 \%$ agarose gel electrophoresis and the gels were stained with GoldView (Beijing Solarbio Science \& Technology Co. Ltd., Beijing, China) before imaging under the UV transilluminator (Bio-Rad, Hercules, CA).

\section{Detection of Viable B. cereus Cells in Spiked Rice, Noodle, and Milk Powder Using PMA-mPCR}

Fresh rice, noodles, and milk powder (Wondersun Inc., Heilongjiang, China) purchased from a local supermarket were used for spiking studies. All the food samples were previously confirmed negative for $\mathrm{B}$. cereus by plate count and standard PCR. Each sample $(25 \mathrm{~g})$ was inoculated with $2.2 \times 10^{1} \mathrm{cfu} / \mathrm{g}$ B. cereus ATCC14579 and mixed with $225 \mathrm{~mL}$ of Luria-Bertani and homogenized for $2 \mathrm{~min}$ ( $\mathrm{Li}$ and Chen, 2013). One milliliter of each enriched cultures was collected at 2, 3, 4 , and $5 \mathrm{~h}$ after incubation at $37^{\circ} \mathrm{C}$ with shaking at 180 $\mathrm{rpm}$. Additionally, to determine whether the presence of non-Bacillus cereus interferes with the detection of viable B. cereus in foods, $10^{5} \mathrm{cfu} / \mathrm{g}$ of Staphylococcus aureus CMCC26001 and Salmonella enteritidis ATCC 13076 were added after the 3 spiked foods (inoculated with $\left.2.5 \times 10^{1} \mathrm{cfu} / \mathrm{g}\right)$ pre-incubation for 4,3 , and $4 \mathrm{~h}$, respectively. The collected samples were centrifuged at $900 \times g$ for $1 \mathrm{~min}$ at $4^{\circ} \mathrm{C}$ to remove large debris, and the suspensions were centrifuged at $12,000 \times g$ for 5 min at $4^{\circ} \mathrm{C}$ (Zhang et al., 2015). The pellets were washed twice and suspended in sterilized water, genome DNA was extracted after PMA pretreatment, and then analyzed by using PMA-mPCR. All of the tests were repeated in triplicate.

\section{RESULTS}

\section{Inclusivity and Exclusivity of PCR Primers}

The specificity of the primers was assessed by inclusivity and exclusivity test using single PCR on 13 spe- cies, including 9 types of common foodborne pathogens (e.g., Escherichia coli O157:H7, Listeria monocytogenes, and Salmonella spp.), and other pathogens (e.g., Candida albicans and Pseudomonas aeruginosa; Table 1). Only B. cereus ATCC 14579 was proven to possess 3 toxic genes (i.e., cytK, nheA, and $h b l D$ ), whereas other microorganisms did not possess these toxic genes.

To avoid false-positive results during PCR processing, a sequencing of the PCR products was performed. The sequence of $3 \mathrm{PCR}$ products was compared in the GenBank database using BLAST (available at http:// blast.ncbi.nlm.nih.gov/Blast.cgi). The results showed that the reliability of cytK, nheA, and $h b l D$ was 96,97 , and $97 \%$, respectively, corresponding to type strain of $B$. cereus ATCC14579. Thus, the primers were reliable for identification of the 3 enterotoxins of B. cereus.

\section{Optimization of Multiplex PCR for Detection of 3 Enterotoxin Genes}

To set up the mPCR method for simultaneous detection of 3 toxic genes of $c y t K$, nhe A, and $h b l D$, a single PCR and mPCR were applied. As shown in Figure 2, all the genes were simultaneously detected, the primers for cytK, nheA, and $h b l D$ produced amplicons of 800 , 617 , and $465 \mathrm{bp}$, respectively.

Considering primer concentration, annealing temperature and cycles might affect the efficiency of $\mathrm{mPCR}$, so several tests were performed by varying annealing temperatures from 49.9 to $60.1^{\circ} \mathrm{C}$, primer concentrations from 0.1 to $0.4 \mu \mathrm{M}$, and cycles from 30 to 35 . Thereafter, the optimal parameters for $\mathrm{mPCR}$ were the combination of concentration of primer for cytK, nheA, and $h b l D$ of $0.175,0.25$, and $0.2 \mu M$, respectively, and optimum annealing temperature at $52.2^{\circ} \mathrm{C}$ as well as cycles of 35 (data not shown).

\section{The Limit of Detection of Cells in Pure Culture with PMA Pretreatment}

To differentiate whether the contamination with $B$. cereus was in state of viable cells or dead cells, we introduced PMA pretreatment for the detection of B. cereus 


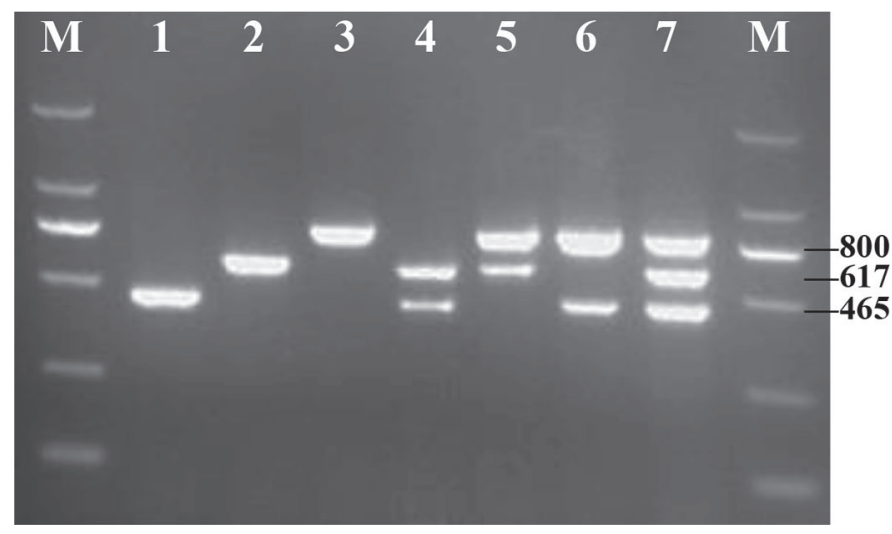

Figure 2. Detection of the 3 enterotoxin genes using single and multiplex PCR. M = DL2000 DNA marker; the 800-, 617-, and 465bp PCR products were produced by the primers for $c y t K$, nheA, and hblD, respectively.

in pure culture by mPCR using optimal conditions as above. As shown in Figure 3, PCR products were performed in lanes by viable cell counts from $5.5 \times 10^{8}$ to $5.5 \times 10^{1} \mathrm{cfu} / \mathrm{mL}$, whereas in lane $8\left(<5.5 \times 10^{2} \mathrm{cfu} /\right.$ $\mathrm{mL})$ no signal was found. In contrast, all the lanes corresponding to $5.5 \times 10^{8}$ to $5.5 \times 10^{1} \mathrm{cfu} / \mathrm{mL}$ dead cells had no signals. The results showed that the limit of detection (LOD) of viable cells was $5.5 \times 10^{2} \mathrm{cfu} / \mathrm{mL}$ in pure culture, which indicated that PMA treatment was efficient and essential before DNA extraction.

\section{Selective Detection of Viable B. cereus in Spiked Foods}

To verify the validity of PMA-mPCR protocol for detection of viable cell count of $B$. cereus in foods, 3 types of spiked foods (milk powder, noodles, and rice) with $2.2 \times 10^{1} \mathrm{cfu} / \mathrm{g}$ of $B$. cereus were investigated. As shown in Figure 4, the protocol determined in pure culture was also suitable for all test foods; namely, below the LOD in pure culture $\left(5.5 \times 10^{2} \mathrm{cfu} / \mathrm{mL}\right)$, the viable cell counts of $B$. cereus could be detected in spiked foods (milk powder, noodle, and rice samples, with an initial inoculation of $2.2 \times 10^{1} \mathrm{cfu} / \mathrm{g}$ ) after enrichment for 4,3 , and $4 \mathrm{~h}$, respectively.

\section{Detection of Viable B. cereus in the Presence of Non-B. cereus and Heat-Killed B. cereus in the Absence of Non-B. cereus in Spiked Foods}

Although the protocol for detection of viable cells was verified in spiked foods, whether the presence of non- $B$. cereus interferes with the protocol is unknown. Therefore, a further verification test was performed on the former assay by additional inoculation of $10^{5} \mathrm{cfu} / \mathrm{g}$ of non-B. cereus; namely, viable cells of Staphylococcus aureus and Salmonella enterica were added after the 3 spiked food pre-incubation for 4,3 , and $4 \mathrm{~h}$, respectively. As shown in Figure 5, positive detection of $B$. cereus in all samples was achieved, confirming the suitability of our protocol as described in Figure 4, and also indicating that non-Bacillus cereus indeed did not affect an accurate detection of this organism.

Moreover, to verify that our protocol could detect viable cells, but not dead cells of $B$. cereus in foods in general, after the same enrichment time with $2.5 \times$ $10^{1} \mathrm{cfu} / \mathrm{g}$ of $B$. cereus, all samples were heated to kill the bacteria and performed with PMA treatment and mPCR assay. Also, shown in Figure 5, negative results were presented, indicating that the method was valid

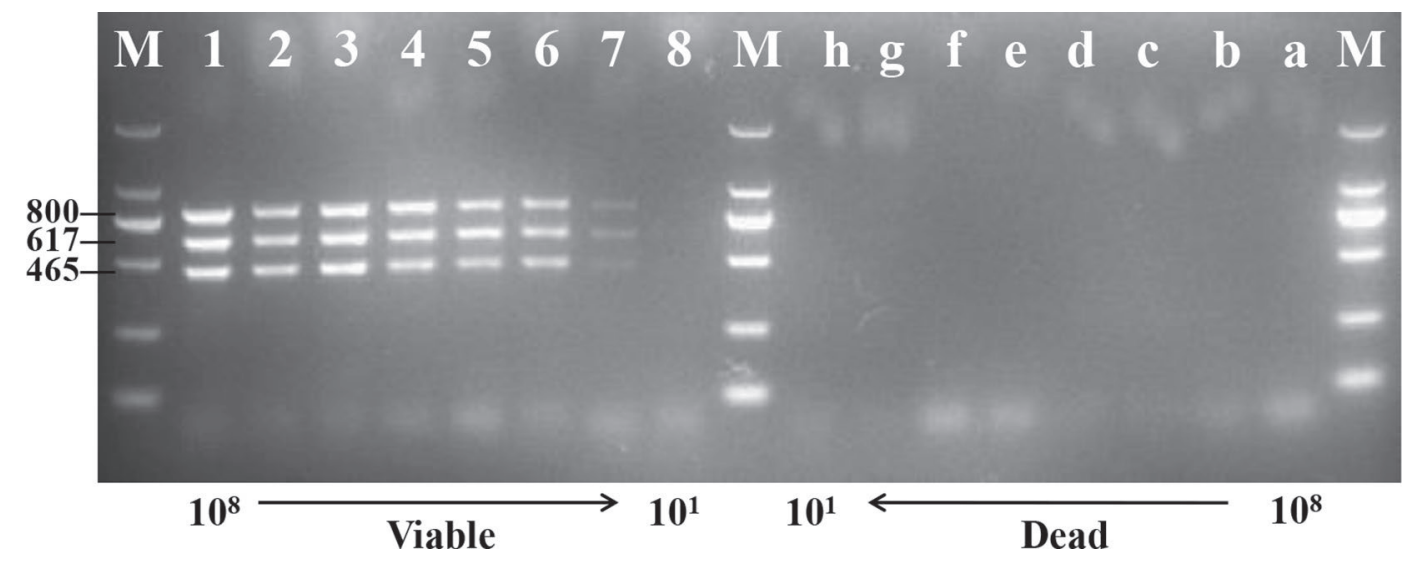

Figure 3. The limit of detection of pure culture Bacillus cereus (viable or dead) using 10-fold serially diluted cultures. Lanes 1 to 8 (or a to h), from $5.5 \times 10^{8}$ to $5.5 \times 10^{1} \mathrm{cfu} / \mathrm{mL}$. Dead cells of B. cereus were prepared by water bath at $100^{\circ} \mathrm{C}$ for 15 min. The DNA was extracted after propidium monoazide pretreatment. $\mathrm{M}=$ DL2000 DNA marker. 

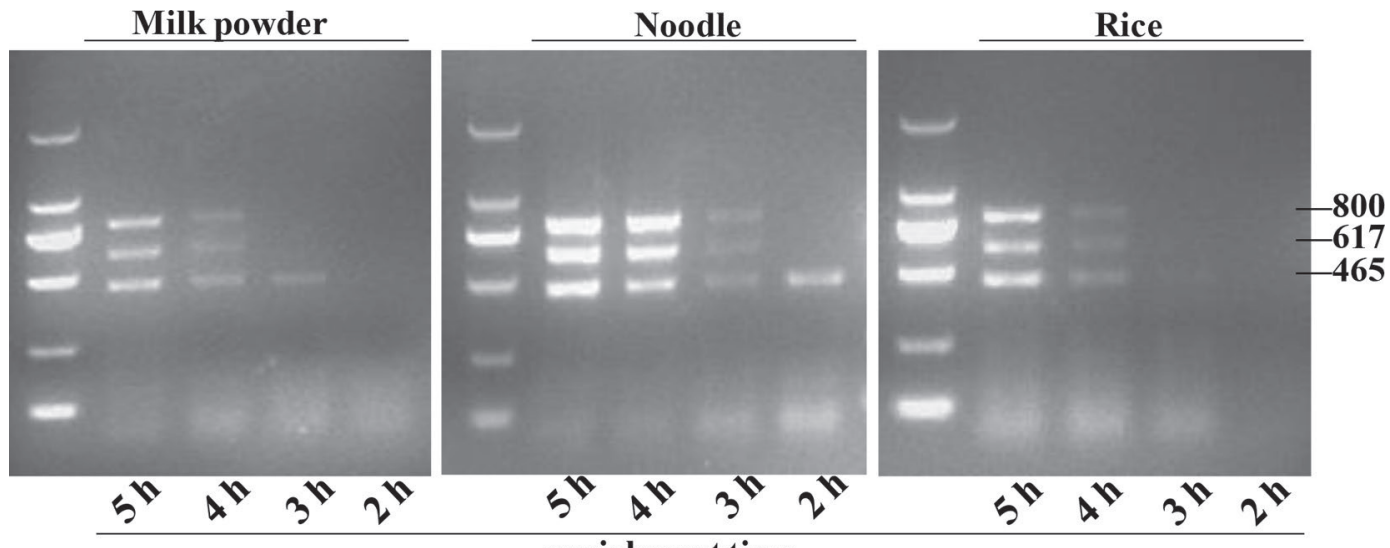

enrichment time

Figure 4. Detection of viable Bacillus cereus spiked in foods by propidium monoazide (PMA)-multiplex PCR. Milk powder, noodles, and rice were inoculated with $2.2 \times 10^{1} \mathrm{cfu} / \mathrm{g}$ of viable cells and incubated at $37^{\circ} \mathrm{C}$ up to $5 \mathrm{~h}$. Samples were collected at different enrichment time points and then treated with PMA before DNA extraction.

to eliminate the amplification signal of dead cells in spiked foods.

\section{Toxigenicity Characterization of B. cereus Isolated from Ready-to-Eat Foods and Infant Formula Milk Powder}

To verify the feasibility of the protocol for detection of epidemic strains of $B$. cereus, an investigation on the distribution of enterotoxin of cytK, nheA, and $h b l D$ in 62 isolates of $B$. cereus was carried out. As shown in Table 3, generally, among all the isolates from noodles, fried rice with egg, fried rice, rice, tikoy, apple butter, pork floss, cooked corn flour, and infant formula milk powder, $34(55 \%)$ harbored the 3 toxic genes of cytK, nhe A, and $h b l D$, but only $3(4.8 \%)$ did not. From noodles, more than $64 \%$ isolates possessed the 3 genes, whereas from cooked corn flour isolates possessing the 3 genes were $17 \%$. The toxic genes, cytK, nheA, and $h b l D$, were harbored in 79,87 , and $61 \%$ of isolates, respectively.

\section{DISCUSSION}

Several DNA-based methods are available for detection of B. cereus; however, most of them targeted qualitative detection of whole cells in the state of dead, or alive and unculturable or culturable. To our knowledge, very few protocols were reported for detecting viable $B$. cereus cells from foods or environmental samples. In this study, a protocol of $\mathrm{mPCR}$ was invented for simultaneous detection of enterotoxin genes of viable $B$. cereus, and therewith toxigenicity of $B$. cereus isolates was characterized. Our protocol was found to be highly specific and sensitive for selective detection of viable cells of $B$. cereus, and PMA pretreatment was able to efficiently eliminate interference of dead cells of B. cereus.

Specific enterotoxin genes (i.e., cytK, nheA, and $h b l D$ ) of $B$. cereus were chosen in the mPCR assay due

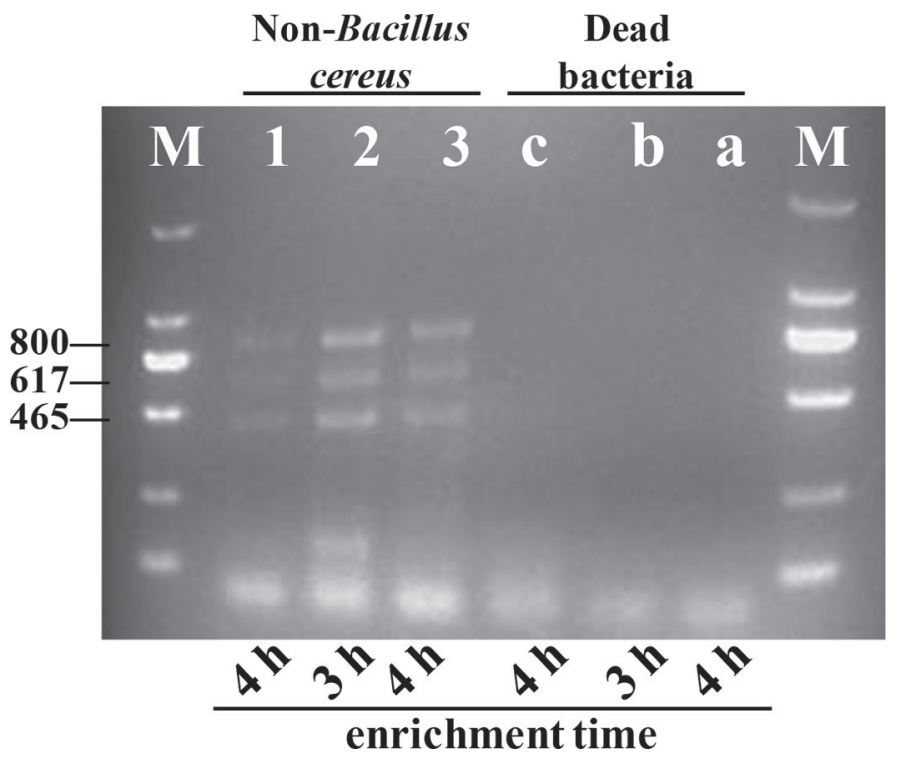

Figure 5. The detection of viable Bacillus cereus in the presence of non-Bacillus cereus and heat-killed B. cereus in the absence of non$B$. cereus in spiked foods by propidium monoazide (PMA)-multiplex PCR. Lanes 1 and a represent contaminated milk powder, lanes 2 and b represent contaminated noodles, and lanes 3 and c represent contaminated rice. All the samples were inoculated with $2.5 \times 10^{1} \mathrm{cfu} / \mathrm{g}$ viable B. cereus. Non- $B$. cereus: spiked samples (1-3) enriched for 4,3 , and $4 \mathrm{~h}$, respectively, and then inoculated with $10^{5} \mathrm{cfu} / \mathrm{g}$ non- $B$. cereus before PMA treatment and DNA extraction. Dead bacteria: spiked samples ( $\mathrm{a}-\mathrm{c}$ ) enriched for 4,3 , and $4 \mathrm{~h}$, respectively, and then heat treatment before PMA treatment and DNA extraction. 
to frequent outbreaks of foodborne diseases (Lund and Granum, 1997; Lund et al., 2000). Those primers were proven to be specific, and the LOD on pure culture of $B$. cereus was $5.5 \times 10^{2} \mathrm{cfu} / \mathrm{mL}$ for viable cells; in contrast, Forghani et al. (2015) proposed a protocol for detection of $B$. cereus at $10^{2} \mathrm{cfu} / \mathrm{mL}$. In their study, the cells might contain dead cells because no treatment by PMA was included. Recently, an improvement in sensitivity of detection for microorganisms was demonstrated (Settanni and Corsetti, 2007); nevertheless, for practical purposes, a direct detection of very low density of viable microbial cells is still unclear. In fact, pathogens (e.g., B. cereus, Staphylococcus aureus, and Salmonella enteritidis) are often present in very low numbers in food (Omiccioli et al., 2009). Thus, an enrichment step is still necessary not only to increase the density of target bacteria in samples but also to recover the physiologically stressed or injured cells (Garrido et al., 2013).

In this study, the spiked food (e.g., milk powder, noodles, and rice) with inoculation as low as $2.2 \times$
$10^{1} \mathrm{cfu} / \mathrm{g}$ was enriched and subsequently detected by PMA-mPCR, and a rapid detection of viable cells of $B$. cereus was completed in 3 or $4 \mathrm{~h}$, even under the interference of non-Bacillus cereus at as high as $10^{5}$ $\mathrm{cfu} / \mathrm{g}$ in foods. The PMA treatment eliminated the false-positive results from dead cells and maintained the validity of $\mathrm{mPCR}$ for the detection of viable cells of $B$. cereus. This is accordance with our previous study (Zhang et al., 2014).

To further expand the application of the protocol, the toxigenicity of $62 \mathrm{~B}$. cereus isolates from readyto-eat foods and infant formula milk powder was characterized. Bacillus cereus produces at least 5 different enterotoxins, including CytK, Nhe, Hbl, EntFM, and BceT. The first 3 toxins are proved to be available in food contaminants, their distribution in food intoxication due to B. cereus is unclear (Hansen and Hendriksen, 2001; Ngamwongsatit et al., 2008; Hwang and Park, 2015), and the previous reports hypothesized that some isolates might cause food poisoning with only 1 or 2 genes among Nhe component or Hbl component,

Table 3. Toxigenicity characterization of Bacillus cereus isolated from ready-to-eat foods and infant formula milk powder

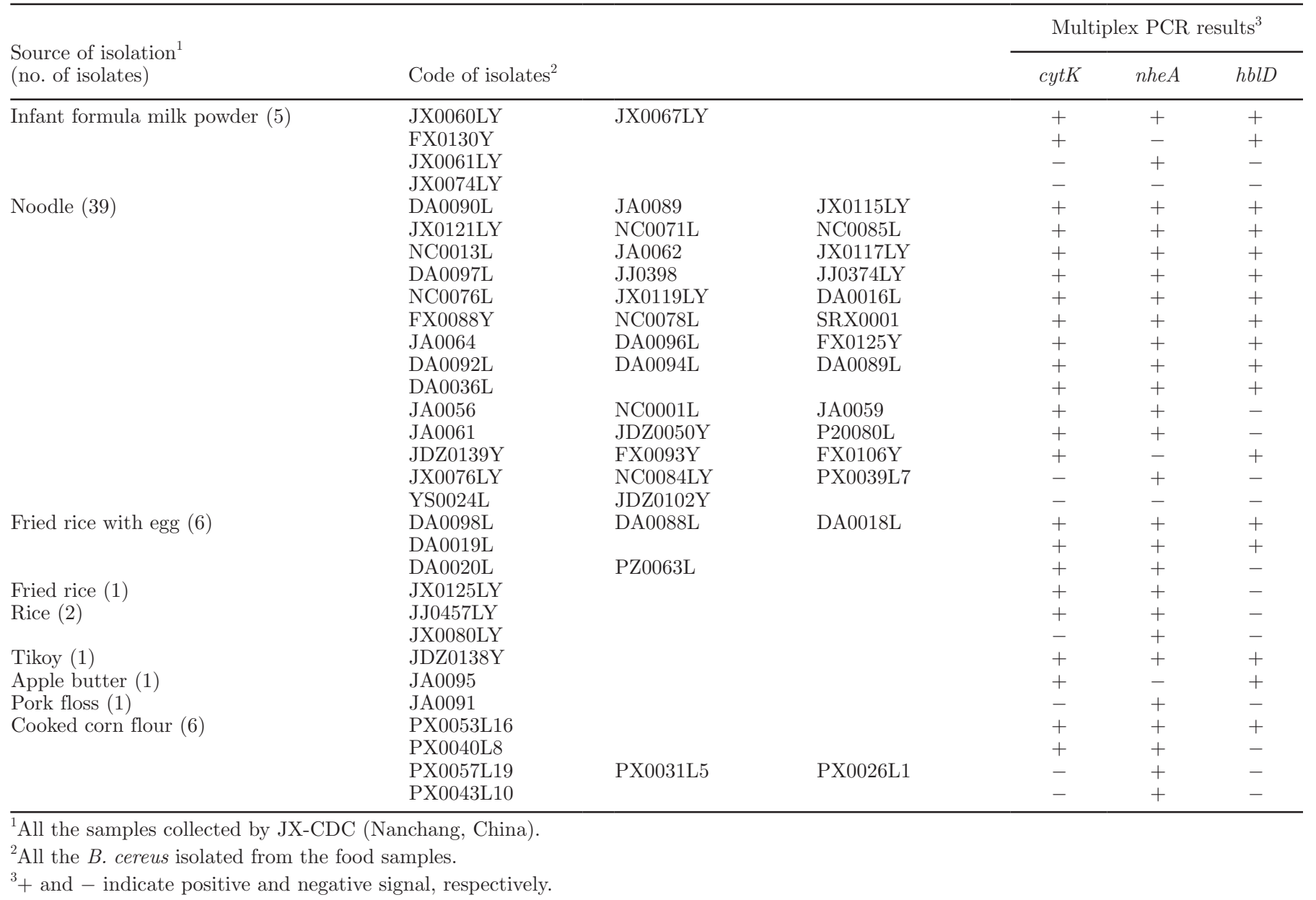


though evidence for their contribution to poisoning is unclear (Hansen and Hendriksen, 2001; Ngamwongsatit et al., 2008; Hwang and Park, 2015). In our study, 79\% strains harbored cytK and more than $61 \%$ strains possessed $h b l D$, which are consistent with previous studies that reported 48 to $77 \%$ and 48.7 to $89 \%$, respectively, of strains harboring cytK and hblD (Ankolekar et al., 2009; Chaves et al., 2012; Chon et al., 2012; Lee et al., 2012; Hwang and Park, 2015). Additionally, more than $87 \%$ of 62 isolates possessed nheA, which is lower than the $100 \%$ of 39 strains of $B$. cereus reported earlier (Lee et al., 2012). Interestingly, 8 strains of 62 isolates possessed only nheA, and no strains possessed only cytk or $h b l D$.

In conclusion, a specific, rapid, and sensitive protocol for detection of viable cells of B. cereus in milk powder, noodles, and rice was developed. By combination of PMA pretreatment and $\mathrm{mPCR}$, a selective detection of B. cereus at $10^{1} \mathrm{cfu} / \mathrm{g}$ from spiked food samples was completed upon 3 or $4 \mathrm{~h}$ of enrichment, and even under the interference from non-Bacillus cereus at a high concentration. Moreover, the toxin gene distribution of $B$. cereus was analyzed with the aid of this protocol, which should be helpful to understand the potential toxigenicity of $B$. cereus in food poisoning cases.

\section{ACKNOWLEDGMENTS}

This work was supported by Academic and Technical Leaders Training Program for Major Subjects of Jiangxi Province (2009), Ganpo Talent 555 Engineering Project of Jiangxi Province, and Graduate Student Innovation Special Funds of Jiangxi Province (YC2015B013), China.

\section{REFERENCES}

Ankolekar, C., T. Rahmati, and R. G. Labbé. 2009. Detection of toxigenic Bacillus cereus and Bacillus thuringiensis spores in US rice. Int. J. Food Microbiol. 128:460-466.

Beattie, S. H. 1999. Detection of toxins. Int. J. Food Sci. Technol. 45:141-148.

Berthold-Pluta, A., A. Pluta, and M. Garbowska. 2015. The effect of selected factors on the survival of Bacillus cereus in the human gastrointestinal tract. Microb. Pathog. 82:7-14.

Bonerba, E., A. Di Pinto, L. Novello, F. Montemurro, V. Terio, V. Colao, G. Ciccarese, and G. Tantillo. 2010. Detection of potentially enterotoxigenic food-related Bacillus cereus by PCR analysis. Int. J. Food Sci. Technol. 45:1310-1315.

Bottone, E. J. 2010. Bacillus cereus, a volatile human pathogen. Clin. Microbiol. Rev. 23:382-398.

Chaves, J. Q., C. F. G. Cavados, and A. M. Vivoni. 2012. Molecular and toxigenic characterization of Bacillus cereus and Bacillus thuringiensis strains isolated from commercial ground roasted coffee. J. Food Prot. 75:518-522.

Chon, J., J. Kim, S. Lee, J. Hyeon, and K. Seo. 2012. Toxin profile, antibiotic resistance, and phenotypic and molecular characterization of Bacillus cereus in Sunsik. Food Microbiol. 32:217-222.
Fagerlund, A., T. Lindbäck, and P. E. Granum. 2010. Bacillus cereus cytotoxins Hbl, Nhe and CytK are secreted via the Sec translocation pathway. BMC Microbiol. 10:304-312.

Forghani, F., T. Langaee, M. Eskandari, K. Seo, M. Chung, and D. Oh. 2015. Rapid detection of viable Bacillus cereus emetic and enterotoxic strains in food by coupling propidium monoazide and multiplex PCR (PMA-mPCR). Food Contr. 55:151-157.

Fricker, M., R. Reissbrodt, and M. Ehling-Schulz. 2008. Evaluation of standard and new chromogenic selective plating media for isolation and identification of Bacillus cereus. Int. J. Food Microbiol. $121: 27-34$.

Garrido, A., M.-J. Chapela, B. Román, P. Fajardo, J. Lago, J. M. Vieites, and A. G. Cabado. 2013. A new multiplex real-time PCR developed method for Salmonella spp. and Listeria monocytogenes detection in food and environmental samples. Food Contr. 30:7685.

Ghosh, A. 1978. Prevalence of Bacillus cereus in the faeces of healthy adults. J. Hyg. (Lond.) 80:233-236.

Hansen, B. M., and N. B. Hendriksen. 2001. Detection of enterotoxic Bacillus cereus and Bacillus thuringiensis strains by PCR analysis. Appl. Environ. Microbiol. 67:185-189.

Hauge, S. 1950. Food poisoning caused by Bacillus cereus. Nord. Hyg. Tidskr. 31:189-206.

Hauge, S. 1955. Food poisoning caused by aerobic spore-forming bacilli. J. Appl. Bacteriol. 18:591-595.

Hwang, J., and J. Park. 2015. Characteristics of enterotoxin distribution, hemolysis, lecithinase, and starch hydrolysis of Bacillus cereus isolated from infant formulas and ready-to-eat foods. J. Dairy Sci. 98:1652-1660.

Jensen, G., B. Hansen, J. Eilenberg, and J. Mahillon. 2003. The hidden lifestyles of Bacillus cereus and relatives. Environ. Microbiol. 5:631-640

Lee, N., J. M. Sun, K. Y. Kwon, H. J. Kim, M. Koo, and H. S. Chun. 2012. Genetic diversity, antimicrobial resistance, and toxigenic profiles of Bacillus cereus strains isolated from Sunsik. J. Food Prot. 75:225-230.

Li, B., and J.-Q. Chen. 2013. Development of a sensitive and specific qPCR assay in conjunction with propidium monoazide for enhanced detection of live Salmonella spp. in food. BMC Microbiol. 13:273.

López, A. C., J. Minnaard, P. F. Pérez, and A. M. Alippi. 2015. A case of intoxication due to a highly cytotoxic Bacillus cereus strain isolated from cooked chicken. Food Microbiol. 46:195-199.

Lund, T., M. L. De Buyser, and P. E. Granum. 2000. A new cytotoxin from Bacillus cereus that may cause necrotic enteritis. Mol. Microbiol. 38:254-261.

Lund, T., and P. E. Granum. 1997. Comparison of biological effect of the two different enterotoxin complexes isolated from three different strains of Bacillus cereus. Microbiology 143:3329-3336.

Ngamwongsatit, P., W. Buasri, P. Pianariyanon, C. Pulsrikarn, M. Ohba, A. Assavanig, and W. Panbangred. 2008. Broad distribution of enterotoxin genes (hblCDA, nheABC, cytK, and entFM) among Bacillus thuringiensis and Bacillus cereus as shown by novel primers. Int. J. Food Microbiol. 121:352-356.

Nocker, A., A. Mazza, L. Masson, A. K. Camper, and R. Brousseau. 2009. Selective detection of live bacteria combining propidium monoazide sample treatment with microarray technology. J. Microbiol. Methods 76:253-261.

Omiccioli, E., G. Amagliani, G. Brandi, and M. Magnani. 2009. A new platform for Real-Time PCR detection of Salmonella spp., Listeria monocytogenes and Escherichia coli O157 in milk. Food Microbiol. $26: 615-622$

Park, S. H., and S. C. Ricke. 2015. Development of multiplex PCR assay for simultaneous detection of Salmonella genus, Salmonella subspecies I, Salm. Enteritidis, Salm. Heidelberg and Salm. Typhimurium. J. Appl. Microbiol. 118:152-160.

Seinige, D., M. von Köckritz-Blickwede, C. Krischek, G. Klein, and C. Kehrenberg. 2014. Influencing factors and applicability of the viability EMA-qPCR for a detection and quantification of Campylobacter cells from water samples. PLoS ONE 9:e113812. 
Settanni, L., and A. Corsetti. 2007. The use of multiplex PCR to detect and differentiate food-and beverage-associated microorganisms: A review. J. Microbiol. Methods 69:1-22.

Singh, V. K., and S. S. A. Chaturvedi. 2015. Study the incidence of Bacillus cereus isolates from dairy foods. Pharma Innovation J. $3: 41-43$.

Stenfors Arnesen, L. P., A. Fagerlund, and P. E. Granum. 2008. From soil to gut: Bacillus cereus and its food poisoning toxins. FEMS Microbiol. Rev. 32:579-606.

van Frankenhuyzen, J. K., J. T. Trevors, H. Lee, C. A. Flemming, and M. B. Habash. 2011. Molecular pathogen detection in biosolids with a focus on quantitative PCR using propidium monoazide for viable cell enumeration. J. Microbiol. Methods 87:263-272.

Velmurugan, S., P. Palanikumar, P. Velayuthani, M. Donio, M. M. Babu, C. Lelin, S. Sudhakar, and T. Citarasu. 2015. Bacterial
White Patch Disease caused by Bacillus cereus, a new emerging disease in semi intensive culture of Litopenaeus vannamei. Aquaculture 44:49-54

Zhang, Z., W. Liu, H. Xu, Z. P. Aguilar, N. P. Shah, and H. Wei. 2015. Propidium monoazide combined with real-time PCR for selective detection of viable Staphylococcus aureus in milk powder and meat products. J. Dairy Sci. 98:1625-1633.

Zhang, Z., L. Wang, H. Xu, Z. P. Aguilar, C. Liu, B. Gan, Y. Xiong, W. Lai, F. Xu, and H. Wei. 2014. Detection of non-emetic and emetic Bacillus cereus by propidium monoazide multiplex PCR (PMA-mPCR) with internal amplification control. Food Contr. 35:401-406. 